\title{
Aplasia segmentar múltipla da medula espinhal em gato
}

\section{Spinal cord multiple segmental aplasia in cat}

\author{
Elisângela Olegário da Silva ${ }^{1}$; Felipe Purcell de Araújo ${ }^{2}$; \\ Mônica Vicky Bahr Arias; ${ }^{3}$ Ana Paula Frederico Rodrigues Loureiro Bracarense ${ }^{4 *}$
}

\section{Resumo}

Malformações congênitas da medula espinhal ocorrem em humanos e animais. Relata-se o caso de um gato sem raça definida de um mês de idade com histórico desde seu nascimento de malformação em membros posteriores. No exame neurológico constatou-se paraplegia, ausência de movimentação da cauda, analgesia e alteração do neurônio motor inferior. Radiografia simples da coluna vertebral lombosacra evidenciou aumento do canal vertebral em L3, L4, L5, L6 e distensão da vesícula urinária. Na necropsia e no exame histopatológico dessa região observou-se apenas resquícios do parênquima medular, raízes nervosas e leptomeninges, o que concluiu o diagnóstico de aplasia segmentar da medula espinhal.

Palavras-chave: Malformação congênita, aplasia segmentar, medula espinhal, gato

\begin{abstract}
Congenital malformations of spinal cord occur in humans and animals. A cat, one month old, mixed breed, presented since birth pelvic limbs malformation. The neurological examination showed paraplegia, absence tail movement, analgesia and lower motor neuron damage. Simple radiography of the lumbarsacral vertebral column showed increased vertebral canal in L3, L4, L5, L6 and distended urinary bladder. Necropsy and histological findings revealed segments of spinal cord parenchyma, nervous roots and leptomeninges. These findings concluded the diagnosis of spinal cord segmental aplasia.
\end{abstract}

Key words: Congenital malformations, segmental aplasia, spinal cord, cat

1 Graduação em Medicina Veterinária/Universidade Estadual de Londrina (UEL)

2 Residência em Clínica Cirúrgica de Animais de Companhia/ UEL

3 Professora Adjunta, depto. Clínicas Veterinárias/UEL

4 Professora Associada, depto. Medicina Veterinária Preventiva/UEL. email: anapaula@uel.br

* Autor para correspondência 


\section{Introdução}

Todos os sistemas do corpo estão sujeitos a malformaçõescongênitas, maso sistemanervosoéum dos mais afetados tanto em humanos (MATUSHITA; PINTO, 2005) como em animais (DE FOREST; BASRUR, 1979). Tais malformações decorrem de defeitos durante a formação do tubo neural e de suas dilatações com conseqüente alterações no prosencéfalo, mesencéfalo, rombencéfalo e medula espinhal, ou de falha na neurogênese, migração e diferenciação neuronais (NORONHA et al., 2001).

A ação de teratógenos como agentes físicos (radiação, hipertermia), químicos, biológicos (infecções virais e bacterianas) ou multifatoriais levam à falha primária no fechamento do tubo neural ou ruptura deste após seu fechamento, gerando malformações congênitas da medula espinhal ou do encéfalo(MAITRA; KUMAR, 2005; MATUSHITA; PINTO, 2005; MAXIE; YOUSSEF, 2007).

Nos gatos, as malformações congênitas causadas por defeitos no fechamento do tubo neural incluem meningocele, anencefalia, exencefalia, meningomielocele, meningoencefalocele e as mielodisplasias (BRAUND, 1994; SUMMERS; CUMMINGS; DE LAHUNTA, 1995; LECOUTER; GRANDY, 2005). Mielodisplasia é um termo que designa malformações na medula espinhal como hidromielia, siringomielia, ausência ou duplicação do canal central, hipoplasia e aplasia segmentar (DE LAHUNTA, 1983; SUMMERS; CUMMINGS; DE LAHUNTA, 1995; LE COUTER; GRANDY, 2005). Em animais, as malformações congênitas mais freqüentes são alterações dos corpos vertebrais (RUSC; KAMINSKI, 2007; NEWITT; GERMAN; BARR, 2008), podendo estar associadas a defeitos na medula espinhal (DE FOREST; BASRUR, 1979; HIRAGA; ABE 2005; CASTRO et al, 2008). A aplasia segmentar é uma malformação raramente relatada em humanos e animais. Esta alteração caracteriza-se pela não formação completa da medula espinhal em alguns segmentos durante a embriogênese (JONES; HUNT; KING, 1997;
MAITRA; KUMAR, 2005). O objetivo deste trabalho é relatar os aspectos clínicos, radiológicos e patológicos de um caso de aplasia segmentar múltipla de medula espinhal em um gato.

\section{Relato de caso}

Relata-se o caso de um gato, atendido no Hospital Veterinário da Universidade Estadual de Londrina, sem raça definida, um mês de idade, com histórico desde seu nascimento de dificuldade de locomoção com membros posteriores.

Ao exame clínico constatou-se impotência funcional de membros posteriores, diminuição da amplitude de movimentos em articulações fêmurotíbio-patelares, distensão abdominal em decorrência de retenção urinária e ulceração em região anal. No exame neurológico observou-se paraplegia, ausência de movimentação da cauda, ausência de reflexos segmentares em membros posteriores, atrofia da musculatura dos membros posteriores e ausência de sensibilidade dolorosa superficial e profunda (Figura 1A).

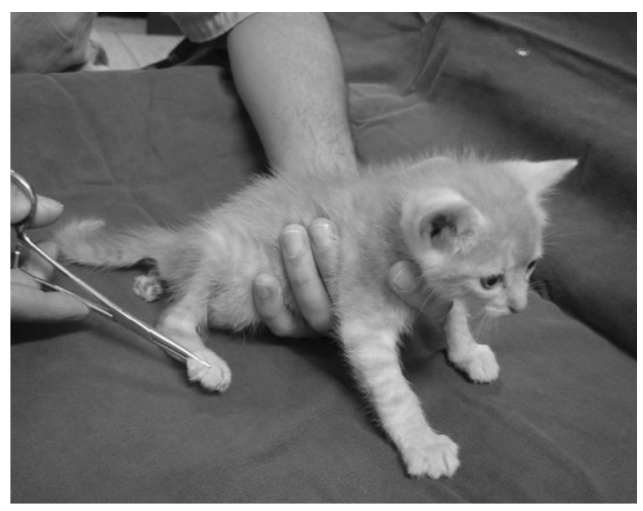

Figura 1A. Felino atendido devido à paraplegia. Observase ausência de resposta ao teste de sensibilidade dolorosa profunda.

$\mathrm{Na}$ radiografia simples da coluna vertebral lombosacra observou-se aumento do diâmetro do canal vertebral em vértebras L3, L4, L5, L6 e distensão da vesícula urinária, que ocupava 
toda cavidade abdominal (Figura 1B). Devido ao prognóstico reservado para retorno à função sensório-motora dos membros e da vesícula urinária, a proprietária optou pela eutanásia do animal.

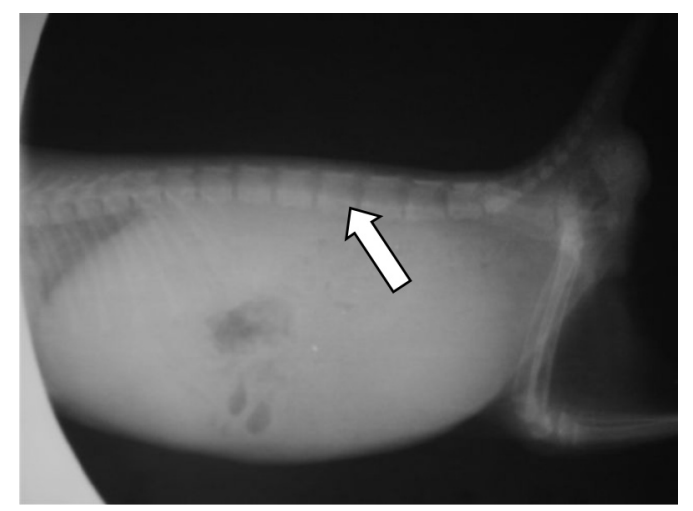

Figura 1B. Radiografia do paciente na qual pode-se observar o aumento do canal vertebral em vértebras L3, L4, L5 e L6 (seta) e distensão da vesícula urinária preenchendo toda a cavidade abdominal.

Ao exame macroscópico observou-se distensão do canal vertebral e acentuada dilatação da medula nos segmentos medulares L4, L5, L6 e L7 com acúmulo de líquido cerebroespinhal em uma cavidade supostamente delimitada pelas meninges. A medula espinhal foi retirada e fixada em solução de formalina tamponada a 10\% (Figura 2A). Após a abertura da dura-máter observou-se presença de resquícios de parênquima medular nessa região (Figura 2 B) o que foi confirmado no exame histopatológico desta região, no qual se constatou a presença apenas de resquícios de raízes nervosas e leptomeninges, confirmando o diagnóstico de aplasia segmentar múltipla da medula espinhal.

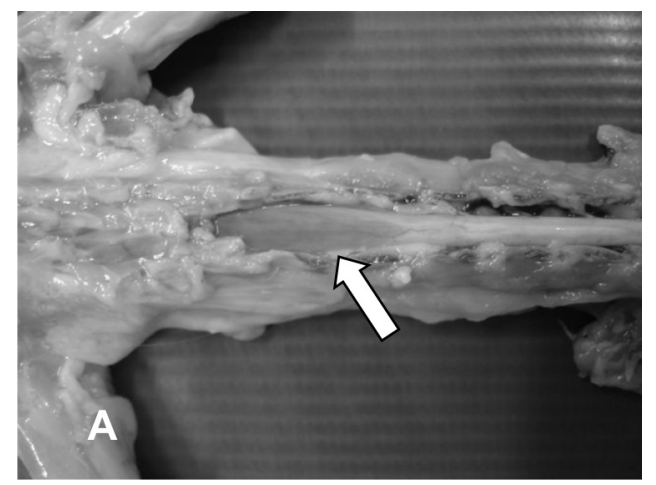

Figura 2A. Imagem macroscópica do aspecto dorsal do canal vertebral do felino, após retirada dos processos espinhosos e lâmina dorsal. Observa-se presença de líquido em segmentos medulares L4, L5, L6 e L7 (seta).

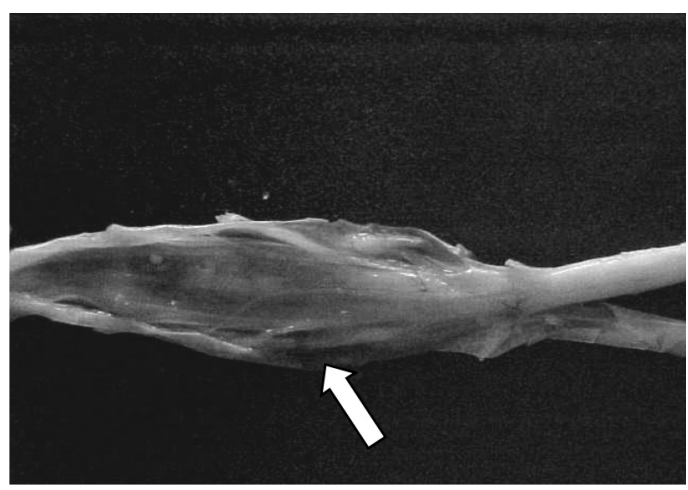

Figura 2B. Fotografia após fixação da medula espinhal e segmentos lombares em formalina $10 \%$ podendo-se observar ausência de parênquima medular em L4, L5, L6 e L7 (seta).

Malformações no sistema nervoso não são infreqüentes, pois uma precisa interação entre notocorda, tubo neural e mesoderme é necessária para o desenvolvimento normal da medula e vértebras (HOPPER; HART, 1985; SUMMERS; CUMMINGS; DE LAHUNTA, 1995). É comum observar emhumanos(MATUSHITA; PINTO, 2005) e animais (BRAUND, 1994; MAXIE; YOUSSEF, 2007) outras malformações associadas com as da medula espinhal, em regiões medulares, tronco cerebral, sistema ventricular e cerebelo, devido à 
estreita ligação no desenvolvimento embriogênico do sistema nervoso (MATUSHITA; PINTO, 2005; MAXIE; YOUSSEF, 2007). Estas malformações congênitas são mais freqüentes na região lombar em humanos (MATUSHITA; PINTO, 2005) e em animais (LE COUTER; GRANDY, 2005; MAXIE; YOUSSEF, 2007; NEWITT; GERMAN; BARR, 2008). Formas mais severas de mielodisplasia em animais ocorrem em associação com a espinha bífida (MAXIE; YOUSSE, 2007), um estado disráfico que freqüentemente acomete os gatos (FENNER, 1994; SUMMERS; CUMMINGS; DE LAHUNTA, 1995; CHRISMAN et al., 2005) e ocorre de maneira similar em humanos (DUARTE et al., 1994; MATUSHITA; PINTO, 2005). O diagnóstico de mielodisplasia é realizado com base no histórico, sinais clínicos, idade, raça, mielografia, análise do líquido cerebroespinhal e confirmado à necropsia e exame histopatológico (LE COUTER; GRANDY, 2005). As mielodisplasias podem acometer qualquer animal doméstico, mas os gatos da raça Manx e os cães da raça Weimaraner são mais predispostos a desenvolvê-las (DE FOREST; BASRUR, 1979; MAXIE; YOUSSEF, 2007).

A medula espinhal pode ser acometida por doenças degenerativas, de origem infecciosa e inflamatória, neoplásicas, traumáticas, congênitas, nutricionais, tóxicas, vasculares e idiopáticas (FENNER, 1994; SCHRADER, 1994; LE COUTER; GRANDY, 2005). Em animais recémnascidos com alterações neurológicas, doenças infecciosas e congênitas são as mais prováveis no rol de diagnósticos diferenciais. A maioria dos casos de hipoplasia e aplasia do cerebelo em gatos são causadas pelo vírus da panleucopenia felina (JONES; HUNT; KING, 1997). Por ser um caso isolado com informações insuficientes fornecidas pela proprietária, não foi possível determinar a causa da malformação congênita da medula espinhal no presente relato.

Em humanos um importante fator materno envolvido na malformação congênita do sistema nervoso é a deficiência de ácido fólico (FROSCH;
ANTHONY; GIROLAMI, 2005; MATUSHITA; PINTO, 2005). Nos gatos, o excesso de vitamina A na alimentação leva ao desenvolvimento de malformações no feto como agenesia da medula espinhal (FREYTAG et al., 2003).

Os sinais clínicos apresentados pelo animal eram semelhantes aos relatados em outros animais com mielodisplasias (SUMMERS; CUMMINGS; DE LAHUNTA, 1995; TUDURY; CAMARGO; GRAÇA, 2000). O animal apresentava além da paraplegia, ausência de resposta ao teste de sensibilidade dolorosa profunda, sendo esta associação normalmente relacionada à aplasia medular (DE LAHUNTA, 1983), devido à falta de vias aferentes ao encéfalo em decorrência da ausência de tecido nervoso na medula espinhal, constatado por meio dos exames de necropsia e histopatologia. Tais exames diferenciam aplasia de hipoplasia segmentar, na qual se observa macroscopicamente afinamento localizado da medula espinhal e microscopicamente depleção neuronal na substância cinzenta com presença de balões axonais na substância branca (TUDURY; CAMARGO; GRAÇA, 2000), sendo escassos os relatos de gatos com tais malformações congênitas (SUMMERS; CUMMINGS; DE LAHUNTA, 1995; TUDURY; CAMARGO; GRAÇA, 2000).

A distensão da vesícula urinária observada na radiografia simples pode ser devido à presença de síndrome lombosacra com conseqüente lesão do tipo neurônio motorinferior, devido ao comprometimento dos segmentos medulares lombares L4, L5, L6 e L7 e possivelmente sacrais, o que torna o músculo detrusor e o esfíncter externo flácidos. Porém, como o nervo hipogástrico, com origem toracolombar, não foi acometido, o esfíncter interno permanece contraído, dificultando o esvaziamento da bexiga. (DE LAHUNTA, 1983).

$\mathrm{Na}$ aplasia segmentar da medula espinhal, os exames hematológicos de rotina, radiografia simples e análise de líquor normalmente estão dentro da normalidade (BRAUND, 1994). É comum ocorrer 
malformação da medula espinhal associada a defeitos do corpo vertebral (DE LAHUNTA, 1983; SUMMERS; CUMMINGS; DE LAHUNTA, 1995).

Neste caso, na radiografia simples foi possível verificar aumento do diâmetro do canal vertebral em vértebras L3, L4, L5 e L6, mas nenhum defeito em corpo vertebral. Este aumento provavelmente foi decorrente do acúmulo de líquor no interior da cavidade delimitada pelas meninges, pois o osso da coluna vertebral de animais jovens é facilmente deformável pela pressão exercida pelo acúmulo progressivo de liquido. Ao exame de necropsia este fato foi confirmado e ao exame histopatológico constatou-se que o líquido estava delimitado apenas pelas meninges, diferenciando tal achado de siringomielia, na qual ocorre acúmulo de líquido em cavitação no parênquima medular (MAXIE; YOUSSEF, 2007).

A aplasia segmentar da medula espinhal é uma malformação congênita raramente diagnosticada em gatos. O sistema nervoso tem uma susceptibilidade singular a uma lesão localizada devido à capacidade estritamente limitada de restaurar a função do tecido danificado, por isso não há tratamento eficaz para aplasia segmentar. Embora os sinais clínicos não progridam e os animais possam sobreviver, o prognóstico é desfavorável (SCHRADER, 1994; LE COUTER; GRANDY, 2005), pois as complicações decorrentes da malformação tornam o prognóstico ruim, não havendo possibilidade de haver recuperação sensorial e motora (TUDURY; CAMARGO; GRAÇA, 2000). Os sinais clínicos, exames laboratoriais e radiográficos nem sempre são conclusivos e os exames de necropsia e histopatologia foram fundamentais para diferenciar esta alteração de outros tipos de mielodisplasias.

\section{Referências}

BRAUND, K. G. Clinical syndromes in veterinary neurology. 2. ed. St. Louis: Mosby, 1994. p. 257-268.

CASTRO, M. B.; SZABÓ, M. P. J.; MOSCARDINI, A. R. C.; BORGES, J. R. J. Perosomus elumbis em um cordeiro no Brasil. Ciência Rural, Santa Maria, v. 38, n. 1, p. 262-265, 2008.

CHRISMAN, C.; MARIANI, C.; PLATT, S.; CLEMMONS, R. Neurologia para o clínico de pequenos animais. São Paulo: Roca, 2005. 336 p.

DE FOREST, M. E.; BASRUR, P. K. Malformations and the manx syndrome in cats. The Canadian Veterinary Journal, Ottawa, v. 20, n. 11, p. 304-314, 1979.

DE LAHUNTA, A. Veterinary neuroanatomy and clinical neurology. 2. ed. Philadelphia: W. B. Saunders Company, $1983.471 \mathrm{p}$.

DUARTE, F.; PITELLA, J. E. H.; ÁVILA, C. M.; ROSEMBERG, S.; HAHN, M. D.; CHIMELLI, L.; DE PAOLA, D. Sistema nervoso. In: FILLO,G. B.; PITELLA, J. E. H.; PEREIRA, F. E. L.; BAMBIRRA, E. A.; BARBOS, A. J. A. Bogliolo-Patologia. 5. ed. Rio de Janeiro: Guanabara Koogan, 1994. p. 723-825.

FENNER, W. R. Diseases of the brain, spinal cord and peripheral nerves. In: SHERDING, R. G. (Ed.). The cat disease and clinical management. 2. ed. New York: Saunders Company, 1994. p. 1507-1568.

FREYTAG, T. L.; LIU, S. M.; ROGERS, Q. R.; MORRIS, J. C. Teratogenic effects of chronic ingestion of high levels of vitamin A in cats. Journal of Animal Physiology and Animal Nutrition, Berlin, v. 87, n. 1/2, p. 42-51, 2003.

FROSCH, M. P.; ANTHONY, D. C.; GIROLAMI, U. The central nervous system. In: KUMAR, V.; ABBAS, A. K.; FAUSTO, N. (Ed.). Robbins and cotran - pathologic basis of disease. 7. ed. Philadelphia: Elsevier Saunders, 2005. p.1347-1419.

HIRAGA, T.; ABE, M. Anatomical observation of six calves affected with segmental aplasia of the spinal cord. The Anatomical Record, New York, v. 219, n. 4, p. 402408, 2005.

HOPPER, A. F.; HART, N. H. The nervous system. In: . Foundations of animal desenvolviment. 2. ed. Oxford: University Press, 1985. p. 479-522.

JONES, T. C.; HUNT, R. D.; KING, N. W. Disturbances of growth: aplasia to neoplasia. In: Veterinary Pathology. 6. ed. Baltimore: Lippincott Willian \& Wilkins, 1997. p. 81-112.

LE COUTER, R. A.; GRANDY, J. L. Diseases of the spinal cord. In: ETTINGER, S. J.; FELDMAN, E. C. Textbook of veterinary internal medicine: diseases of the dog and cat. 6. ed. St. Louis: Elsevier Saunders, 2005. p.842-887. $1 \mathrm{v}$. 
MAITRA, A.; KUMAR, V. Diseases of infancy and childhood. In: KUMAR, V.; ABBAS, A. K.; FAUSTO, N. (Ed.). Robbins and cotran - pathologic basis of disease. 7. ed. Philadelphia: Elsevier Saunders, 2005. p.469-508.

MATUSHITA, H.; PINTO, F. C. G. Mielomeningocele. In: DIAMENT, A.; CYPEL, S. (Coord.) Neurologia infantil. 4. ed. São Paulo: Ateneu, 2005. p. 759-772. 1 v.

MAXIE, M. G.; YOUSSEF, S. The nervous system. In: MAXIE, M. G. (Ed.). Jubb, Kennedy and Palmer's - Pathology of domestic animals. 5. ed. Philadelphia: Elsevier Saunders, 2007. p. 281-457. 1 v.

NEWITT, A.; GERMAN, A. J.; BARR, F. J; Congenital abnormalities of the feline vertebral column. Veterinary Radiology Ultrasound, Raleigh, v. 49, n. 1, p. 35-41, 2008.

NORONHA, L.; MEDEIROS, F.; MARTINS, V. D. M.; NONES, R. B.; SEPULCRI, R. P.; PREVEDELLO, L. M. S.; SAMPAIO, G. A.; SERAPIÃO, M. J.; TORRES,
L. F. B. A neuropatologia no período neonatal: análise de 1616 casos de necropsia. Arquivos de Neuro Psiquiatria, São Paulo, v. 59, n. 2B, p. 411-416, 2001.

RUSC, A.; KAMINSKI, S. Prevalence of complex vertebral malformation carrier among Polish HolsteinFriesian bulls. Journal of Applied Genetics, Poznan, v. 48, n. 3, p. 247-252, 2007.

SCHRADER, S. C. Neurosurgery. In: SHERDING, R. G. (Ed.). The cat disease and clinical management. 2. ed. New York: Saunders Company, 1994. p. 1577-1598.

SUMMERS, B. A.; CUMMINGS, J. F.; DE LAHUNTA, A. Malformations of the central nervous system. In: p. 68-94. . Veterinary Pathology. St. Louis: Mosby, 1995.

TUDURY, E. A.; CAMARGO, P. L.; GRAÇA, D. L. Mielodisplasia segmentar múltipla em gato. Ciência Rural, Santa Maria, v. 3, n. 3, p. 529-531, 2000. 